\title{
Determination the drop trajectory of a lost plane Juanjuan $\mathrm{Hu}$
} North China Electric Power University, Baoding 071000,China

Keywords: drop trajectory; kinesiology; lift force; resistance; Bernoulli equation.

Abstract. When we search a lost plane, the first question we should solve is how to locate the original fall area. Establishing the force equilibrium equation of plane, we study the drag force and the lift force based on lift principle in Fluid mechanics.

\section{The search range model}

The aircraft will "shake hands" with service counter in a certain time. Assuming time interval of " shake hands" are 30 minutes. If the "handshake" behavior with the service counter doesn't happen at the "handshake" time, we can assume that the plane has dropped in the time interval of last "handshake" to this "handshake" time. Crash time is assumed obeying uniform distribution in the range of fall, the expected time of the crashed aircraft:

$$
E(t)=\frac{t_{1}+t_{2}}{2}
$$

If we want to know the area of the plane crash, we should calculate the plane crashed position in the ocean surface at the expected time.

Assume that the resistance is in direct proportion to the square of velocity: $f=\frac{1}{2} \rho V^{2} C_{d} S$ (assumingk $=\frac{1}{2} \rho C_{d} S$, drag coefficient)

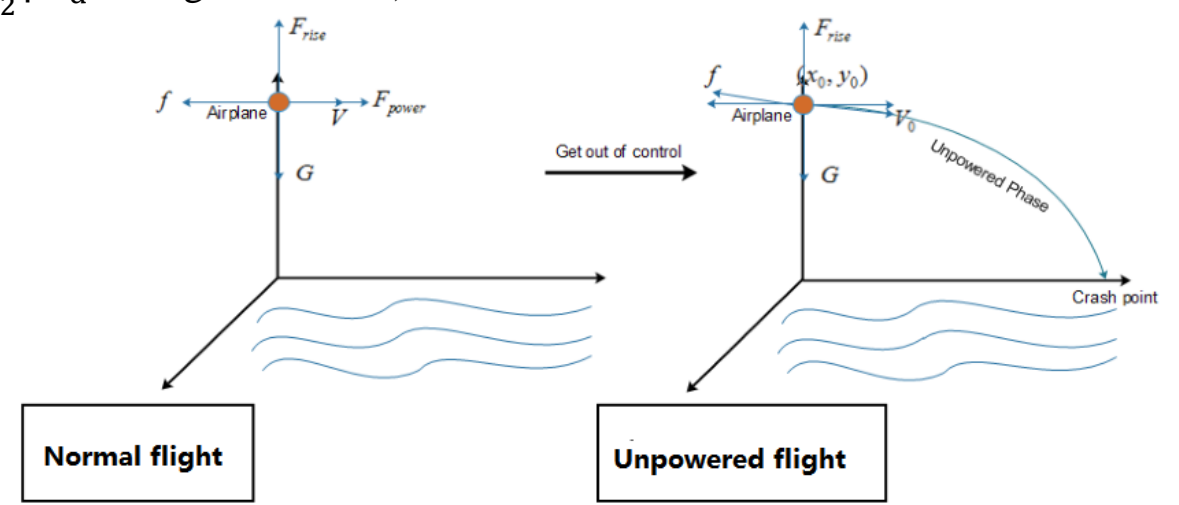

After force analysis, according to kinematics formula:

$$
\frac{\mathrm{d}^{2} \overrightarrow{\mathrm{x}}}{\mathrm{dt}^{2}}=\mathrm{mg}+\overrightarrow{\mathrm{f}}+\overrightarrow{\mathrm{F}_{\mathrm{r} \text { se }}}
$$

Assuming that lift force $\mathrm{F}_{\text {rise }}$ only act in vertical direction, the it can be decomposed into two directions under rectangular coordinate system:

Horizontal direction

Vertical direction

$$
\mathrm{m} \frac{\mathrm{d}^{2} \mathrm{x}}{\mathrm{dt}^{2}}=-\mathrm{k}\left(\frac{\mathrm{dx}}{\mathrm{dt}}\right)^{2}
$$

$$
\mathrm{m} \frac{\mathrm{d}^{2} \mathrm{~h}}{\mathrm{dt}^{2}}=\mathrm{mg}-\mathrm{k}\left(\frac{\mathrm{dh}}{\mathrm{dt}}\right)^{2}-\mathrm{F}_{\text {rise }}
$$

Put into the initial conditions $h(0)=h_{0}, x(0)=x_{0}$, using matlab to solve then simplify the result:

$$
\mathrm{x}=\frac{\mathrm{m}}{\mathrm{k}} \log \left(\mathrm{e}^{\frac{\mathrm{kx} \mathrm{x}_{0}}{\mathrm{~m}}}+\frac{\mathrm{k}}{\mathrm{m}} \mathrm{e}^{\frac{\mathrm{kx}_{0}}{\mathrm{~m}}} \mathrm{~V}_{\mathrm{x} 0} \mathrm{t}\right)
$$




$$
\mathrm{h}=\mathrm{h}_{0}-\sqrt{\frac{\mathrm{mg}-\mathrm{F}_{\text {rise }}}{\mathrm{k}}} \mathrm{t}+\frac{\mathrm{m}}{\mathrm{k}} \log \left(2\left(\mathrm{e}^{\left(\frac{1}{\mathrm{~m}^{2}}\left(\mathrm{mg}-\mathrm{F}_{\text {rise }}\right) \mathrm{kt}^{2}\right)}+1\right)\right)
$$

Form the upper formula, we know that wanting to know the desired crash site, we must know the initial position $\left(\mathrm{x}_{0}, \mathrm{~h}_{0}\right)$ unpowered flight. Air resistance $\mathrm{f}$, and lift force $\mathrm{F}_{\text {rise }}$, the above equation does not solve $F_{\text {rise }}$, so we should solveF $\mathrm{F}_{\text {rise }}$

After data query, we know the lift coefficient:

$$
\mathrm{c}_{\mathrm{L}}=\frac{2 \mathrm{~F}_{\text {rise }}}{\rho S \mathrm{~V}_{0}^{2}} \Leftrightarrow \mathrm{F}_{\text {rise }}=\frac{1}{2} \mathrm{c}_{\mathrm{L}} \rho S \mathrm{VV}_{0}{ }^{2}
$$

Through querying, wecan get some common plane data:

\begin{tabular}{|c|c|c|c|c|c|c|c|}
\hline \multicolumn{7}{|c|}{ The datas of commom planes } \\
\hline Types of plane & $777-200$ & $777-200 \mathrm{ER}$ & 767 & $747-8$ & 737 & A300-600 & A310-300 \\
\hline $\begin{array}{c}\text { Maximum Takeoff } \\
\text { Weight(Kg) }\end{array}$ & 247200 & 297550 & 186880 & 447696 & 66000 & 165000 & 150000 \\
\hline Typical Cruise Speed(Mach) & 0.84 & 0.84 & 0.8 & 0.845 & 0.785 & 0.8 & 0.8 \\
\hline Wing Span(m) & 60.9 & 60.9 & 47.6 & 68.5 & 34.3 & 44.84 & 43.89 \\
\hline
\end{tabular}

Assuming that we used Malaysia Airline System MH370 Boeing 777Fas model to calculate, we know that the wing area $S \approx 100 \mathrm{~m}^{2}$, full load weightm $=3 * 10^{5} \mathrm{~kg}$, air density $=0.9 \mathrm{~kg} / \mathrm{m}^{3}$, lift

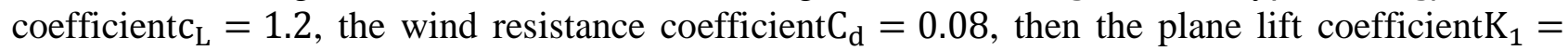
$\frac{1}{2} c_{L} \rho S=54 \mathrm{KG} / \mathrm{m}^{2}$, assuming before plane lost power the cruising altitudeh $\mathrm{h}_{0}=10000 \mathrm{~m}$, cruising speedV $V_{0}=240 \mathrm{~m} / \mathrm{s} . \mathrm{k}=\frac{1}{2} \rho \mathrm{C}_{\mathrm{d}} \mathrm{S}=3.2 \mathrm{~kg} / \mathrm{m}$.then wecan simulate the crashed flying curve of the unpowered:

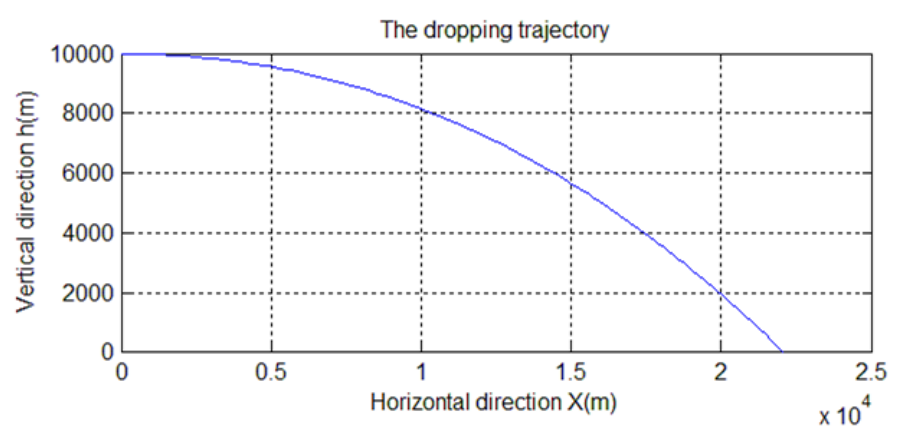

According to the trajectory of unpowered plane, we can see the horizontal distance between the location when plan losing power and location when the plane crashed on ground is $22352 \mathrm{~m}$ (matlab program is attached in appendix 2).

Through the above formula we can calculate the approximate location of the crashed plane. Taking the location of the crashed plane as the center, use a certain radius of the circle to search the plane. As shown in the figure below:

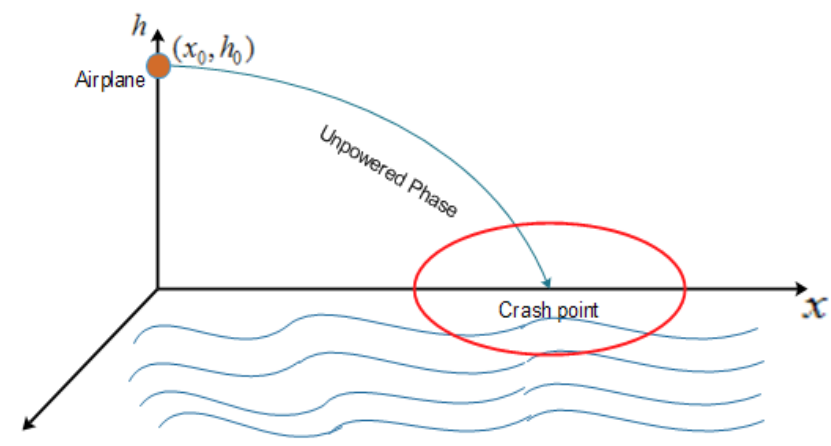




\section{Sensitivity analysis:}

In the process of modeling, we made some assumptions. Although we have explained the assumptions, we cannot guarantee the completeness and accuracy of the assumptions. However, from the last "hand shake"of data transmission it has been a certain period of time, so the plane's speed is not known at that time. Then we should analyze the value: as for the plan velocity before crashing, it has different curve. We take $V_{0}$ as the unknown parameters, then when working out the lift force, the lift c impact curve is:

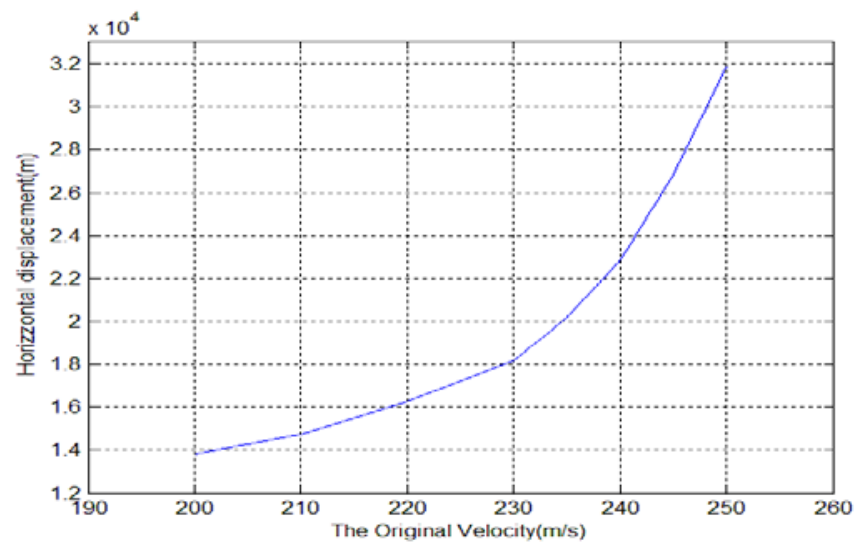

(Sensitivity curve of initial velocity V0 from the plane drop point after losing power to the point $\mathrm{x}$ when the plan lost power) from the figure above, we list parts of different initial velocity and corresponding different point distance:

Sensitivity of initial velocity from the plane drop point after losing power to the point $\mathrm{x}$ when the plan lost power

\begin{tabular}{|c|l|l|l|l|l|l|}
\hline initial velocity (v0) & 250 & 245 & 240 & 235 & 230 & 225 \\
\hline Drop point distance & 31872 & 26825 & 22352 & 20125 & 18135 & 16875 \\
\hline
\end{tabular}

In the available range of plan initial velocity:

If the variation of $\mathrm{x}$ is $\Delta \mathrm{x}$, then the relative variation of $\mathrm{x}$ is $\mathrm{x} / \Delta \mathrm{x}$, the variation of $\mathrm{V}_{0}$ is $\Delta \mathrm{V}_{0}$, then the relative variation of $\mathrm{V}_{0}$ is $\mathrm{V}_{0} / \Delta \mathrm{V}_{0}$. The specific value of two relative variations is the specific value of $\mathrm{x} / \Delta \mathrm{x}$ and $\mathrm{V}_{0} / \Delta \mathrm{V}_{0}$. When $\Delta \mathrm{V}_{0} \rightarrow 0$, then:

$$
\frac{\mathrm{x} / \Delta \mathrm{x}}{\mathrm{V}_{0} / \Delta \mathrm{V}_{0}} \rightarrow \frac{\mathrm{dx}}{\mathrm{dV}} \cdot \frac{\mathrm{V}_{0}}{\mathrm{x}}
$$

So, the limit value is Sensitivity from $x$ to $V_{0}$, it is written as $S\left(x, V_{0}\right)$. In this problem, when $\mathrm{V}_{0}=245, \mathrm{x}=26825$, we get:

$$
\mathrm{S}\left(\mathrm{x}, \mathrm{V}_{0}\right)=\frac{\mathrm{dx}}{\mathrm{dV_{0 }}} \cdot \frac{\mathrm{V}_{0}}{\mathrm{x}}=9.4
$$

If the initial velocity increases by $1 \%$, the range of drop point increases by $9.4 \%$, through reasonable calculation of initial velocity, we can get:

$$
\mathrm{S}\left(\mathrm{x}, \mathrm{V}_{0}\right) \geq 3.75
$$

Because of the difference of initial flight height, the drop point distance will be influent in the end.

\section{Reference}

[1] Si Shoukui, Sun Yuxijing. Mathematical modeling algorithms and applications Beijing: National Defense Industry Press 2014. 2. 347-349.

[2] Xiong Xiaofeng, Yong Senyong. Dynamics analysis of movement process after wedge fell into the water. School of Science Zhejiang Sci-tech University

[3] Chen Wenwen, Zhang Wei. Fluid mechanics [M] Tianjin: Tianjin University Press, 2004. 